\title{
Settlement below embankments: factors controlling the depth of the deformation zone
}

\author{
Zsolt Rémai \\ University of Technology and Economics, Budapest, Hungary
}

\begin{abstract}
The issue of settlement and the calculation of the thickness of the deformation zone are addressed in this paper. A short overview is given concerning the thickness of the deformation zone values used in general practice; the available soil models are also briefly introduced. A particular problem is used to compare the results of obtained depth of the influence zone calculated by available formulae and estimated by finite element analyses with different soil models, such as the "hardening soil", the "CamClay" and the "hardening soil with small strain" models. The deformation zone of a soft clay layer beneath a $10 \mathrm{~m}$-high and $80 \mathrm{~m}$-wide embankment is evaluated, and the results are compared. Special attention is given to the soil models and their capabilities and drawbacks for calculation of deformations due to large embankments.
\end{abstract}

Key words: embankment, settlement, depth of deformation, FE analysis, small strain

\section{Introduction}

Recent highway projects in Hungary have highlighted the need for reliable settlement prediction in the case of high and wide embankments. This requires proper understanding of stress-strain characteristics of the soil and adequate modelling of soil behavior. The latter includes not only the selection of a suitable soil model that fits the experimental results, but also those that account for the thickness of compressible soil and other factors affecting the depth of deformation zone beneath the embankment. Soil deformation below the deformation zone is considered to be insignificant. The depth of the deformation zone has a great influence on the predicted settlements: if a thicker soil zone is taken into consideration, as a consequence settlement is increased. There are numerous methods to determine the depth of deformation; however, these can result in very different values. In this paper an overview is given of recent formulae and of the possibilities of finite element (FE) analysis in settlement calculation. An example is analyzed to illustrate the advantages and the limitations of these methods.

\section{Methods of settlement prediction}

Settlement prediction methods can be divided into two groups: i) closed formulae and ii) numerical methods (e.g. the FE method). While closed formulae

Address: Zs. Rémai: H-1111 Budapest, Múegyetem rkp.3, Hungary; e-mail: remai@vnet.hu Received: September 18, 2012; accepted: May 5, 2014 
generally provide results for quick calculations, due to the use of simplified soil behavior analyses, the methods of the second group can take into account more complex soil behavior (e.g. non-linear behavior or soil property-dependent stress distribution), but are computationally more difficult.

In all cases the accuracy of the settlement prediction is defined by two factors: the deformation properties of the soil and the thickness of the compressive soil layer. The deformation properties can be defined by linear or non-linear stressstrain relationships. Obviously, the better the real soil behavior is approximated, the better the prediction is. The other very important factor is the thickness of the compressed layer, which is defined by the depth of deformation zone. This work focuses on issues regarding proper estimation of the depth of the deformation zone.

\section{Simplified formulae for deformation zone}

There are numerous simple expressions available for settlement calculation, but with the spreading of computer programs, these methods have been used mostly for preliminary, rough estimations. The depths of deformation zone values recommended by different methods are generally defined as a function of foundation width and applied load (or stress increment in underlying soil mass). A summary of the proposed deformation depth values is given in Table 1.

Earlier methods proposed a function of foundation width, but in recent practice this is generally determined based on a calculated stress distribution in the soil mass. The depth at which the stress increment decreases to a certain percentage of the initial overburden stress is considered to be the depth of deformation zone. In recent times a value of $20 \%$ is used in Hungarian and German practice. However, Széchy and Varga (1968) have found that this percentage can be as high as 50\% in the case of large surface loadings, and very recent back-analyses of Kempfert (2006) resulted in an average of $25 \%$. The difference is significant, and it is most likely because the thickness of deformed zone is more a function of strain than a function of stress; the small, negligible deformations (below the zone of deformation) may be governed by the small strain stiffness of the soils.

\section{Finite element methods and deformation zone}

FEM programs enable making detailed calculations of stress distribution using different soil models and deformation parameters. However, when deep zones are considered in FE calculations, larger settlement values are obtained, so the maximum deformation depth must be defined by the user (by properly defining the model area) in advance. There are many soil models that can be used in FE analyses; four of them are discussed in this paper. 
Table 1

Recommendations for the calculation of maximum depth of deformation

\begin{tabular}{|c|c|c|}
\hline Method & $\begin{array}{c}\text { Depth of } \\
\text { deformation zone }\end{array}$ & Comment \\
\hline $\begin{array}{l}\text { Jáky (1944) } \\
\text { (in Farkas 1995) }\end{array}$ & $\begin{array}{l}2 \mathrm{~B} \cdot(1-\mathrm{B} / 2 \cdot \mathrm{L}) \\
\text { for strip: } 2 \mathrm{~B}\end{array}$ & $\begin{array}{l}\text { " } \mathrm{B} \text { " is the foundation width } \\
\text { " } \mathrm{L} \text { " is the foundation length, for strip foundations: } \mathrm{L}=\text { ? }\end{array}$ \\
\hline $\begin{array}{l}\text { De Beer (1978) } \\
\text { (in Kaniraj 1988) }\end{array}$ & $4 \mathrm{~B}$ & " $\mathrm{B}$ " is the foundation width \\
\hline $\begin{array}{l}\text { Egorov and Malikova } \\
\text { (1975) }\end{array}$ & $\xi \cdot\left(B \cdot q^{2} / p^{2}\right)^{0.5}$ & $\begin{array}{l}\text { Proposed for large surface area }(B>10 \mathrm{~m}) \text { slab foundations } \\
\text { " } \xi \text { " is an empirical coefficient: } \\
\xi=6 \text { for clayey soils and } \xi=4 \text { for sandy soils } \\
\text { "q" is the average load intensity on soil } \\
\text { "p" is a reference pressure, } p=300 \mathrm{kPa}\end{array}$ \\
\hline $\begin{array}{l}\text { DIN } 1054 \\
\text { MSZ 15004-1989 }\end{array}$ & "20\%" & $\begin{array}{l}\text { at depth where the stress inc rement decreases below } 20 \% \\
\text { of overburden effective stress }\end{array}$ \\
\hline $\begin{array}{l}\text { Széchy and } \text { Varga } \\
(1968)\end{array}$ & "50\%" & $\begin{array}{l}\text { for large surface area foundations } \\
\text { at depth where the stress inc rement decreases below } 50 \% \\
\text { of overburden effective stress }\end{array}$ \\
\hline Kempfert (2006) & $25 \%$ & $\begin{array}{l}\text { based on } 10 \text { back analysis of slab foundations } \\
\text { at depth where the stress inc rement decreases below } 25 \% \\
\text { of overburden effective stress }\end{array}$ \\
\hline
\end{tabular}

The linear elastic perfectly plastic soil model (or Mohr-Coulomb model) is perhaps the simplest one. It does not take into account the change in stress with deformation and a constant Young's modulus is used for the calculation of the deformation field. Soil models that uses isotropic compression hardening are considered as better approximations. For larger average normal stress these soil models predict more rigid soil behavior and for larger deviatoric stresses larger deformations are considered. In these models the stress-strain behavior is generally described by a power or a logarithmic function. These models enable better settlement prediction by using a larger deformation modulus over larger stress ranges (i.e. at larger depths).

There is also a recently developed soil model available in the PLAXIS 2010 finite element software, which incorporates isotropic stress hardening and stiffer soil behavior in the small-strain range. It is referred to as a "Hardening soil model with small strain stiffness" ("HSsmall").

\section{Settlement prediction of 10 M-high embankment}

\section{Geometry, soil properties}

A simplified model was used to analyze the possibilities, limitations, advantages and disadvantages of the available approaches of the calculation of deformation zone by using the example of a large embankment built on soft soils. The model is based on the recent project of the Hungarian M43 highway. The embankment height, crown and base width are $10 \mathrm{~m}, 40 \mathrm{~m}$ and $80 \mathrm{~m}$, respectively. Consequently, the inclination of the embankment slope is $2: 1$. The underlying soil 
consisted of a single soft clay layer. Its properties were defined based on laboratory and in-situ tests. The defined geotechnical model is shown in Fig. 1. The density and shear strength parameters of the embankment and the underlying soft clay are given in Table 2 . The used soil models and the defined deformation properties of the soft clay are summarized in Table 3.

\section{Finite element analyses}

The soil models employed describe the nonlinear soil behavior in different ways. The stress hardening soil model, unlike a linear elastic - perfectly plastic model, takes into account the nonlinearity of stress-strain behavior. The deviatoric stress - axial strain relationship is approximated by a hyperbolic function, and stress dependency of the oedometer modulus is described by a power function.

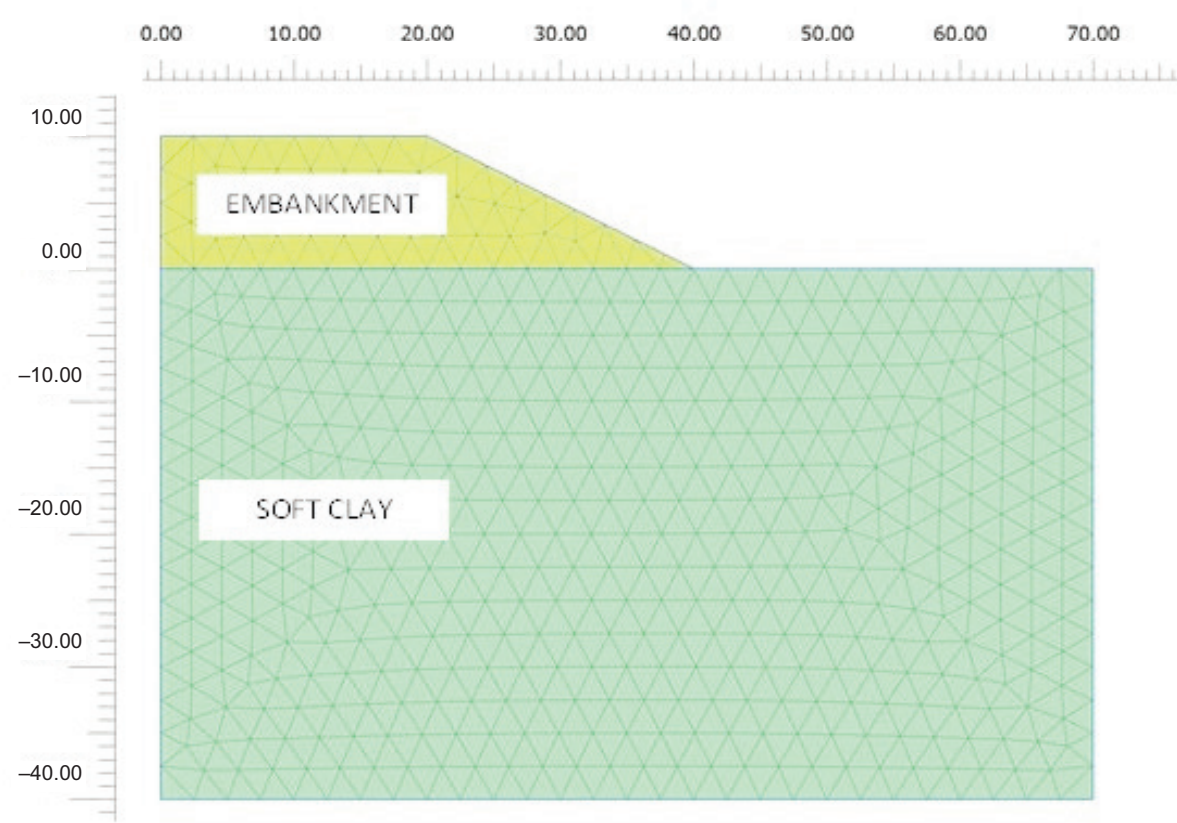

Fig. 1

Geotechnical model

Table 2

Soil physical properties used in model calculations

\begin{tabular}{|l|c|c|c|c}
\hline Soil type & $\begin{array}{c}\gamma_{\text {unsat }} \\
\text { Unsaturated unit weight } \\
{\left[\mathrm{kN} / \mathrm{m}^{3}\right]}\end{array}$ & $\begin{array}{c}\gamma_{\text {sat }} \\
\text { Saturated unit weight } \\
{\left[\mathrm{kN} / \mathrm{m}^{3}\right]}\end{array}$ & $\begin{array}{c}\varphi^{\prime}, \text { Angle of internal } \\
\text { friction (effective) }\left[{ }^{\circ}\right]\end{array}$ & $\begin{array}{c}\mathrm{c}^{\prime}, \text { cohesion } \\
\text { (effective) } \\
{[\mathrm{kPa}]}\end{array}$ \\
\hline Embankment & 16 & 19 & 30 & 1 \\
\hline Soft clay & 17 & 19 & 25 & 1 \\
\hline
\end{tabular}


Table 3

Deformation properties

\begin{tabular}{|c|c|c|c|c|c|}
\hline Soil model & $\begin{array}{c}\mathrm{E}, \mathrm{E}_{50}^{\text {ref }} \\
\text { Young's } \\
\text { modulus }[\mathrm{kPa}]\end{array}$ & $\begin{array}{c}\mathrm{E}_{\mathrm{oed}}, \mathrm{E}_{\mathrm{oed}}{ }^{\mathrm{rel}} \\
\text { Oedometer } \\
\text { modulus } \\
{[\mathrm{kPa}]}\end{array}$ & $\begin{array}{c}\lambda,(\text { Cam-clay }) \\
\text { compression index } \\
{[-]}\end{array}$ & $\begin{array}{l}\mathrm{G}_{0} ; \text { Reference shear modulus (at } \\
\left.\text { very small strain, } ?<10^{-6}\right)[\mathrm{kPa}]\end{array}$ & $\begin{array}{c}\gamma_{0.7} ; \text { Shear stra in at } \\
\text { which Gs }=0.7 \mathrm{G}_{0} \\
{[-]}\end{array}$ \\
\hline $\begin{array}{l}\text { Linear elastic-perfectly } \\
\text { plastic (Mohr-Coulomb) }\end{array}$ & 4000 (E) & $5000\left(\mathrm{E}_{\mathrm{oed}}\right)$ & & & \\
\hline $\begin{array}{l}\text { Isotropic stress hardening } \\
\text { (Hardening soil) }\end{array}$ & $4000\left(\mathrm{E}_{50}{ }^{\mathrm{ref}}\right)$ & $5000\left(\mathrm{E}_{\text {oed }}^{\text {ref }}\right)$ & & & \\
\hline $\begin{array}{l}\text { Hardening soil model with } \\
\text { small strain stiffness }\end{array}$ & $4000\left(E_{50}{ }^{\text {ref }}\right)$ & $5000\left(\mathrm{E}_{\text {oed }}{ }^{\text {ref }}\right)$ & & 50000 & $4 \cdot 10^{-4}$ \\
\hline Cam-Clay & & & 0.04 & & \\
\hline
\end{tabular}

The Cam-Clay model defines the deformation characteristics of the soil based on the theory of critical-state soil mechanics, and assumes a logarithmic relationship between void ratio and mean effective stress.

In addition to the hardening soil model, the "hardening soil with small strain" model also takes into account the much stiffer soil behavior at small strain. Such stiffer response is well known in soil dynamics (Atkinson and Salfors, 1991); however, the more rigid behavior was thought to be caused by the dynamic nature of loading and not by small-strain responses. Recent experiences have shown that even for static loading the soil behavior is more rigid in smaller stress ranges. This is described by a stiffness modulus degradation curve (Fig. 2), where the stiffness modulus is a function of the actual shear-strain increment. It has been found that the normalized curves have a very similar shape for different soil types, and the curve can be defined by two parameters: the small-strain shear modulus, $G_{0}$, and the shear strain at which $G=0.722 G_{0}$, i.e. $\gamma_{07}$. As illustrated in Fig. 2, the small-strain deformation characteristics cannot be tested by conventional geotechnical methods. They must be obtained from specialized tests or empirical correlations.

\section{Small-strain deformation properties}

There are several laboratory and in situ tests available to determine the smallstrain stiffness of soils. The most frequently-used laboratory tests are triaxial tests with local strain gauges or bender elements, the resonant column test, and the torsional shear test. In situ tests (typically seismic tests) are also often used to measure small-strain stiffness; the most typical are the seismic CPT and downhole or crosshole tests. A detailed summary of recently used methods is provided by Benz (2007).

There are also numerous empirical correlations available in which the smallstrain modulus is related to common geotechnical parameters such as overconsolidation ratio, void ratio, undrained shear strength and CPT or SPT values. An example, proposed by Mayne and Rix (1993), is shown in Fig. 3.

In addition to the small-strain stiffness, it is the shape of the degradation curve that defines deformation characteristics in the small-strain range. As mentioned 


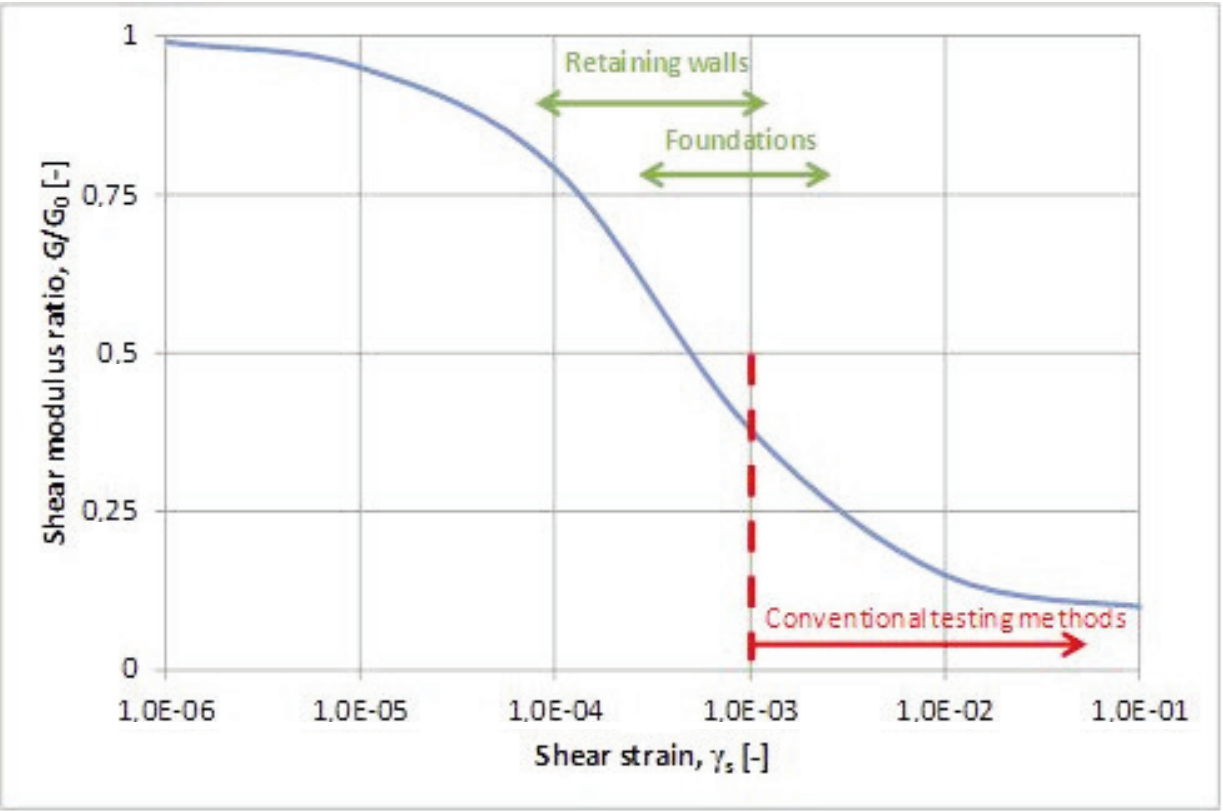

Fig. 2

Small strain stiffness degradation (Atkinson and Salfors 1991)

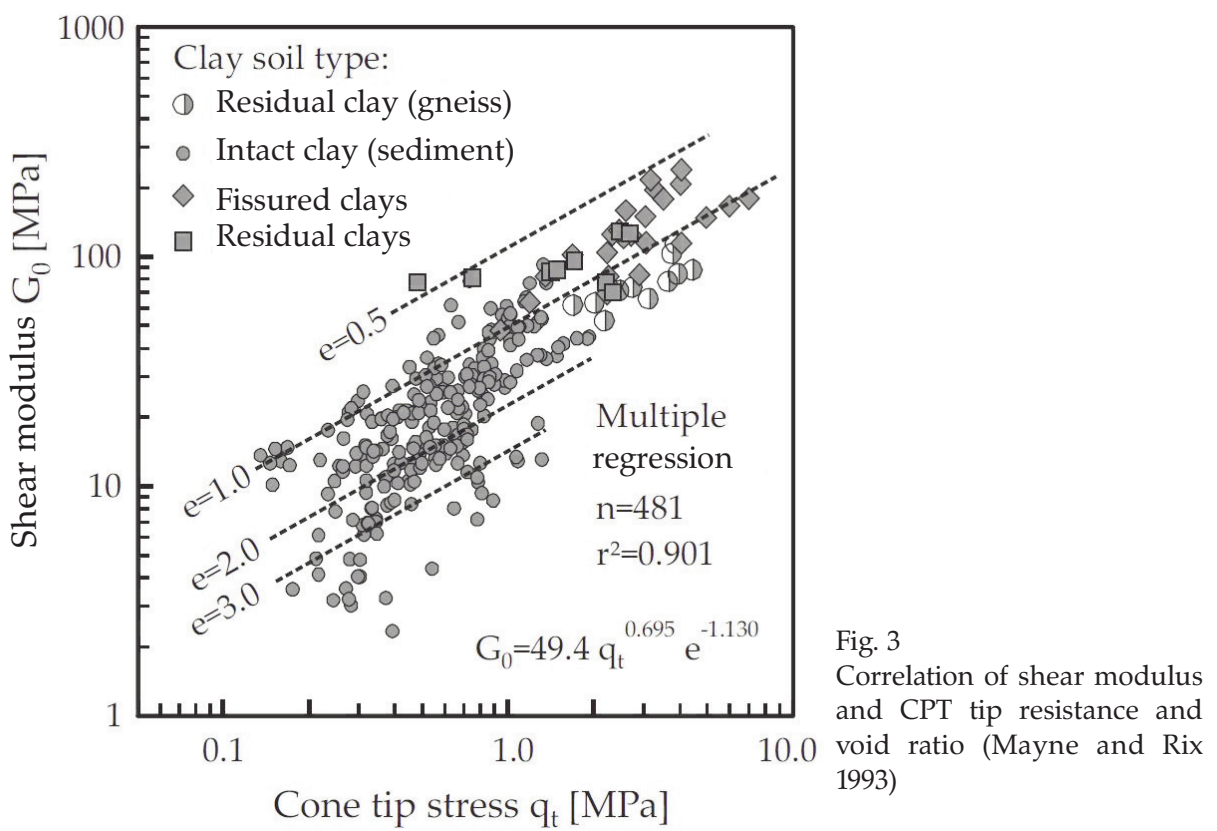


above, this can be determined with reference to $\gamma_{0.7}$. Other than through measurement, empirical correlations can be used to estimate this value. There are many factors (e.g. confining stress, loading history, void ratio, plasticity) that have an effect on the degradation curve, and therefore also many empirical correlation for estimating it. In the case of cohesive soils, plasticity seems to be the most important factor. Benz (2007) has summarized numerous degradation curves for soils having different plasticity (Fig. 4).

Fig. 4

Degradation curves of clayey soils (Benz 2007)

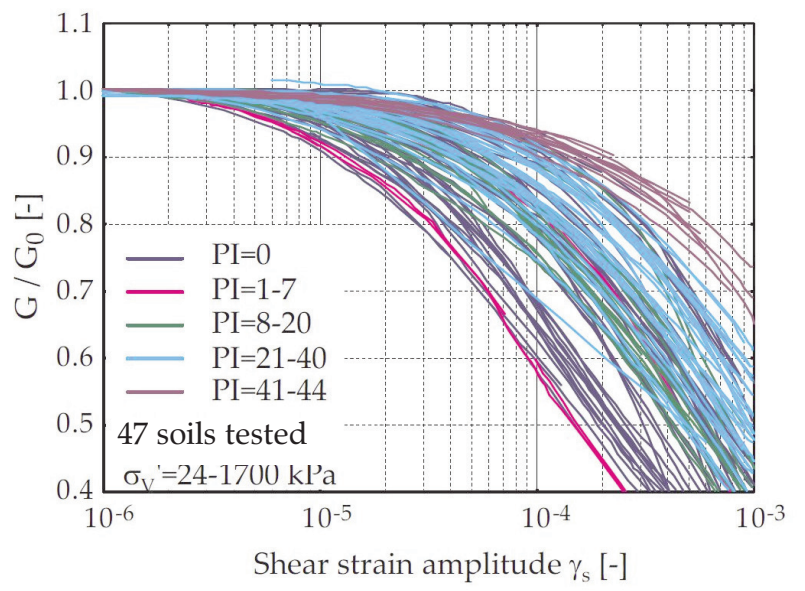

The mentioned correlations can provide a helpful guideline if no other data is available; however, care must be taken when using the proposed relationships in a different geologic environments.

\section{Depth of deformation zone - Closed formulae}

The calculated maximum depth of deformations using the simplified methods for the previously-described embankment is shown in Table 4. The methods of Jáky and De Beer for narrow strip foundation produce substantially larger depths of deformations than the other ones and seem to overestimate this value. The other methods provide better approximations. However, the maximum depth of the deformed zone still shows wide ranges of variations, with values between 21.5 and $41 \mathrm{~m}$.

\section{Depth of deformation zone - FE analyses}

FE analyses with different model depths were performed using the mentioned soil models. Model depths of 30, 40,50 and $60 \mathrm{~m}$ were used and the calculated maximum settlement values were plotted against these depths (Fig. 5). As mentioned previously, the deformation parameters were defined based on the test results. 
Table 4

Calculated maximum depth of deformation

\begin{tabular}{|l|c|}
\hline Method & Maximum depth of deformation [m] \\
\hline Jáky method (Farkas 1995) & 160 \\
De Beer method (Kaniraj 1988) & 320 \\
\hline Egorov and Malikova (1975) & 21.5 \\
DIN 1054 & 41 \\
MSZ 15004-1989 & 20 \\
\hline Széchy and Varga method (Farkas 1995) & 35 \\
\hline Kempfert (2006) & \\
\hline
\end{tabular}

A clear tendency can be observed. The linear elastic-perfectly plastic (MohrCoulomb) model gives much larger settlement values than the more sophisticated models. The results seem to increase nearly linearly with model depth; thus, using this particular model requires proper location of the model's bottom boundary (depth of deformation zone).

The results calculated by the isotropic stress-hardening model and the CamClay model are less dependent on model depth, but the difference in the case of the former is still not negligible. The results obtained by the Cam-Clay model seem to be more realistic. At greater depth, the curve tends to the vertical, but there is still $7 \mathrm{~cm}$ (about 10\%) of settlement difference between the calculations in the case of the $40 \mathrm{~m}$ and $60 \mathrm{~m}$-model depths. In addition, no specific rupture-

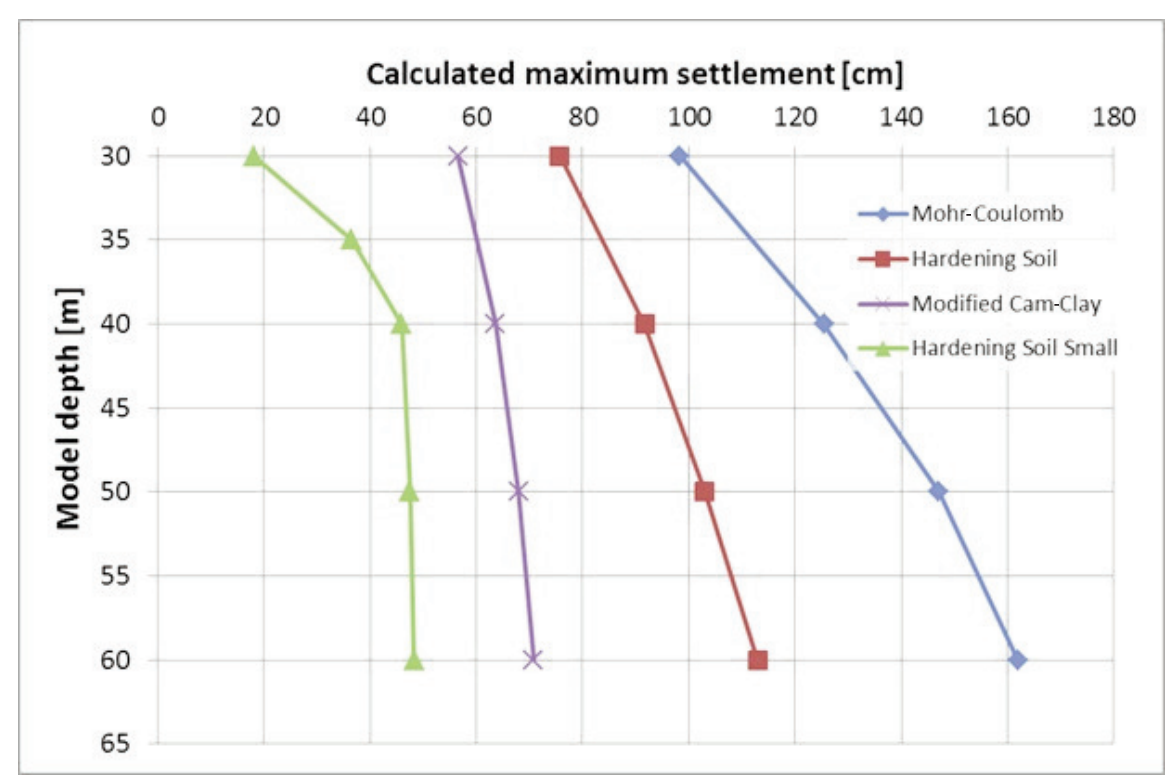

Fig. 5

Calculated maximum settlement vs. model depth 
point can be observed. Therefore it is difficult to define an exact depth of deformation based on the shape of the curve. For these soil models, the calculated settlement values still depend on model depth, but the effect is less significant. When using a larger model area the calculated settlement increased by only about $10-20 \%$.

The calculations performed using the HSSmall model have shown even better results. There is a significant difference between the result obtained from models applied to depths of $30 \mathrm{~m}$ and $40 \mathrm{~m}$, but further increases in model depth did not result in significant increase in maximum settlement. The difference of the calculated settlements was only $2.3 \mathrm{~cm}$ (about 5\%) for the $40 \mathrm{~m}$ and $60 \mathrm{~m}$ model depths. This soil model provides fairly good results, independently of the defined model depth.

These FE results imply that the maximum depth of deformation for this specific case is about 35 to $40 \mathrm{~m}$. This is in good agreement with the values calculated according to the guidelines given in the German and Hungarian standards and with the recent experiences of Kempfert (2006). Obviously the depth of deformation approximated by the FE analyses depends on the input deformation parameters of the models. For this calculation, the large-strain parameters (i.e. Young modulus, Oedometer modulus) were defined by laboratory test, and the small-strain stiffness was based on available empirical correlations. A more reliable estimation could be provided by determining the small-strain behavior of soils using laboratory or in situ tests.

The surface settlements determined by using a $40 \mathrm{~m}$-deep model and different soil models are shown in Fig. 6. The shape of the curves are quite similar for the first three soil models, but in the case of the HSSmall soil model the analysis resulted in much smaller deformations at the toe and outside the embankment. This latter shape is in good agreement with recent embankment settlement monitoring experiences. This also implies that taking into account the soil's smallstrain stiffness in a more accurate way results in better estimation of the soil deformation.

\section{Summary and conclusion}

A number of approaches are available for estimating the depth of deformation for settlement calculations and many of these are used in everyday practice. The depth of the deformed zone for a $10 \mathrm{~m}$-high embankment was determined by using some of the recently-used formulae, but the results are scattered over a very wide range. Finite element analyses were also performed to determine deformations for this particular embankment. Several soil models (hardening, HSSmall, Cam-Clay) were used to calculate deformations of the underlying soft clay layer. It was found that insignificantly small soil deformations occur below a certain depth (i.e. depth of deformation) due to the soil's greater stiffness in the small-strain range. The maximum depth of deformation evaluated by FE analyses 


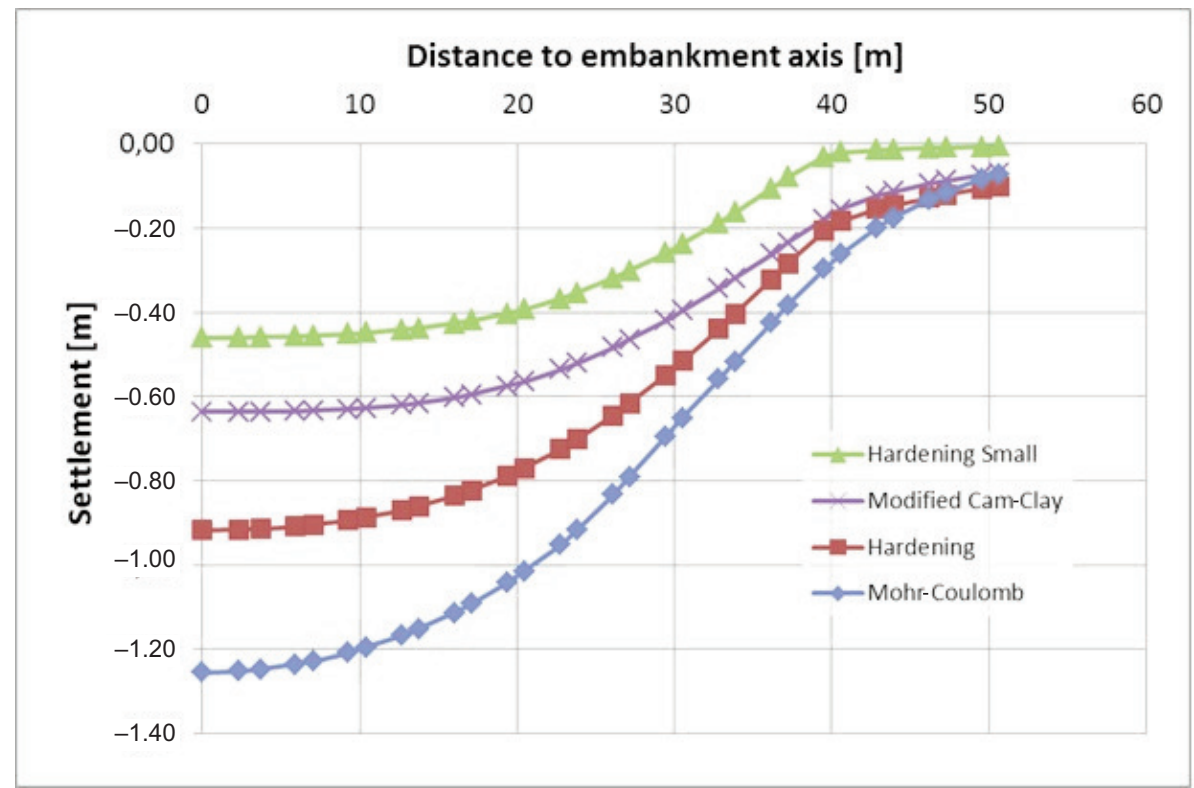

Fig. 6

Calculated surface settlements

was in good agreement with the proposed values of DIN1054, MSZ15004 and Kempfert (2006). Although these references define the maximum depths of deformations in terms of stresses (at a depth where the stress increment decreases to a certain percentage of the effective overburden stress), they do seem to accurately predict the stress level at which the deformation, is governed mostly by small-strain stiffness.

It was also found that the hardening and Cam-Clay soil models overestimate soil deformation slightly, especially at greater depth (i.e. in small-strain zones). Therefore the use of these soil models requires a careful definition of the model depth, i.e. the bottom boundary should be at the maximum depth of deformation. Using the HSSmall soil model, the significant deformation zone can be determined in a fairly reliable way. Taking into account small-strain stiffness, the FE analyses result in nearly the same settlement results, independently of the defined model area, thus enabling more reliable settlement calculations.

\section{References}

Atkinson, J.H., G. Salfors 1991: Experimental deformation of soil properties. - Proceedings of 10th European Conference on Soil Mechanics and Geotechnical Engineering, Vol. 3, pp. 915-956. Benz, T. 2007: Small strain stiffness of soils and its numerical consequences. - Mitteilung 55. des Instituts für Geotechnik, Universität Stuttgart, Germany. 
Egorov, K.E., T.A. Malikova 1975: Settlement of foundation slabs on compressible base. -5 th Asian Regional Conference on Soil Mechanics and Foundation Engineering, Bangalore, Vol. 1, pp. 187190.

Farkas, J. 1995: Foundation engineering. - Múegyetemi Kiadó, University textbook, Budapest University of Technology and Economics.

Kaniraj, S.R. 1988: Design aids in soil mechanics and foundation engineering. - Tata McGraw-Hill, New Delhi, 514 p.

Kempfert, H.G. 2006: Excavations and foundations in soft soils. - Springer Verlag, Berlin Heidelberg, $576 \mathrm{p}$.

Mayne, P.W., G.J. Rix 1993: Gmax-qc relationships for clay. - Geotechnical Testing Journal, 16/1, pp. 54-60.

Plaxis, Material Models Manual 2010 - (http://www.plaxis.nl/files/files/2D2010-3-MaterialModels_02.pdf)

Széchy, K., L. Varga 1968: Foundation engineering.- University textbook, Budapest University of Technology and Economics. (In Hungarian.) 